\title{
CLIMATE CHANGE SCENARIOS FOR AN ASSESSMENT OF VULNERABILITY OF FORESTS IN UKRAINE IN THE $21^{\text {st }}$ CENTURY
}

\author{
Svitlana KRAKOVSKA ${ }^{1}$, I. BUKSHA ${ }^{2}$, A. SHVIDENKO ${ }^{3}$
}

\begin{abstract}
Climate change scenarios for an assessment of vulnerability of forests in Ukraine in the 21st century. Forests are among the most valuable resources of any country not only as wood, but as a key component of bio-ecological system. Excluding anthropogenic factors, forests are mostly vulnerable by wildfire, droughts, pest invasions, hazardous and extreme weather events, etc. In fact, all these non-anthropogenic impacts could be significantly intensified by projected climate change in the 21st century. That is why future conditions for sustainable forest growth should be evaluated accounting for projected climate change preferably under different scenarios. It is well known that global climate change reveals different regional aspects. Therefore, special scenarios have been elaborated processing data of regional climate models (RCMs) from the FP-6 project ENSEMBLES with spatial resolution of $25 \mathrm{~km}$. Verified over the territory of Ukraine ensembles of $10 \mathrm{RCMs}$ for air temperature and 4 RCMs for precipitation calculated for IPCC scenario A1B, which is characterized by balanced consumption of fossil and renewable energy sources and considered by climate change science as one of most likely future development of the world, were applied. Taking into account that the expected dryness of regional climate could generate major challenges for vulnerability of Ukrainian forests, a modification of A1B scenario that is characterized by increasing temperature and decreasing precipitation (A1B+T-P) was proposed. In overall, the impacts of climate change on Ukrainian forests are diverse dependently upon geographical location, geomorphology and large land forms (mountains, plains), forest types and regimes of forest management. The biggest vulnerability was recognized in forests growing in steppe and southern forest steppe, where there is a high probability of impoverishment, degradation and death of forests over large areas. At the same time, there is also a threat of critical increase of vulnerability in other regions, particularly under more tough scenarios of climate change. The study was supported via the EU-funded ClimaEast project CEEF2015-036-UA "Building capacity for the assessment of vulnerability of Ukraine's flatland forests to climate change”.
\end{abstract}

Keywords: climate change scenario, forest vulnerability, regional climate model, climate index,

Corresponding author: Ukrainian Hydrometeorological Institute, Kyiv, Ukraine, e-mail: krasvit@ua.fm

2 Ukrainian Research Institute of Forestry and Forest Melioration named after G.M.Vysotskyi, Kharkiv, Ukraine, e-mail: buksha@uriffm.org.ua

3 International Institute for Applied Systems Analysis, Laxenburg, Austria, e-mail: shvidenko@iiasa.ac.at 


\section{INTRODUCTION}

Among 17 goals of sustainable development for period of 2016-2030, which were accepted by the UN Summit-2015, Goal 13 is - «Take urgent action to combat climate change and its impacts». This goal defines a necessity of urgent actions on overcoming of undesirable consequences of climate change. One of major ways to reach Goal 13 in forest management of Ukraine is transition to sustainable (adaptive) forest management, which foresees considering the impact of climate change on forests and use of proactive strategies in forest management. In order to implement these two prerequisites, the reliable long term predictions of future trajectories of forests under climate change, including their vitality, resilience to disturbances, productivity and health should be developed.

Ukraine's forests are already being affected by climate change and the significance of these impacts is likely to increase in the course of the century. The 5th Assessment Report of Intergovernmental Panel on Climate Change (IPCC, 2013) suggests that under the most likely climate change scenarios the conditions for growth of forest vegetation in Eastern Europe will significantly deteriorate in the next 20-30 years, accelerating this negative tendency to the end of the $21^{\text {st }}$ century. However, the specific impact of climate change on Ukraine's forests had not been researched in detail until now.

The presented study was based on the previously obtained results in Ukrainian Hydrometeorological Institute (UHMI) where changes and absolute values of main climatic characteristics for three 20-year periods in the $21^{\text {st }}$ century in comparison to the standard WMO (1961-1990) and modern period (1991-2010) were elaborated. Since generally the use of an ensemble of several (at least three) models always is an advantage due to possibility to get not only the determined average value, but possible limits, which present such important characteristics as climate variability, the ensembles of numerical models with assessment of corresponding confidential intervals (CI) were also used in this study. All calculations were based on data of Regional Climate Models (RCM), derived from European project ENSEMBLES [ensembles-eu.metoffice.com], IPCC Scenario A1B (Nakićenović and Swart 2000). It was shown in UHMI that under formation of the optimal ensemble of RCMs for Ukraine, it was reasonable to select 10 RCMs for analysis of temperature change. However, only 4 RCMs were estimated as suitable for analysis of precipitation. In addition, one of the models had no data on precipitation for period of 2081-2100, thus for this period the ensemble has consisted of 3 RCMs. (Krakovska et al. 2013). Spatially distributed data on temperature and precipitation named E-OBS (Haylock et al., 2008) of the project ECA\&D [http://www.ecad.eu] were used for assessment of current climate change.

The study was supported via the EU-funded ClimaEast project CEEF2015036-UA "Building capacity for the assessment of vulnerability of Ukraine's flatland forests to climate change". 


\section{SCENARIOS OF CLIMATE CHANGE IN UKRAINE}

The newest climatic scenarios from the AR5 IPCC (2013) are named as Representative Concentration Pathways (RCP) and divided in RCP2.6, RCP4.5, RCP6.0 and RCP8.5, where the numbers denote the summarized radiation impacts in $\mathrm{W} / \mathrm{m}^{2}$ (IPCC, 2013). Quantitavely, increase of the global air temperature by the new scenarios are comparable with previous scenarios SRES: by end of the century RCP4.5 and SRES B1 have practically the same anomalies of the global air temperature at $2^{\circ} \mathrm{C}$; $\mathrm{A} 2$ is «softer» than the most tough RCP8.5, and A1B - «more tough» than RCP6.0. As it was noted above, the projection by IPCC SRES B1, A2 and A1B of change of basic and some of specialized climatic indicators have been obtained in UHMI, and they were included to the 3rd, $4^{\text {th }}$ and $5^{\text {th }}$ National Communications of Ukraine on climate change to UNFCCC. These results and quantitative scenarios for Ukraine were used and continue to be used for estimations of future development of energetic, water, agro-industrial and other resources of the country (Gnatiuk et al. 2013).

To give the overall view of recent and projected climate change in Ukraine, ombroregime or climate humidity is one of the best indicators. The simplest generalizing ombroregime characteristic is the ratio of annual precipitation to potential evaporation (approximated by maximum month temperature) that gives dimensionless coefficient of humidification by VysotskyIvanov served for climate typologization. Maps of humidification coefficients with corresponded types of climates for all considered climatic periods are presented at Fig.1. It is obvious, that shifting to North and North-West of drier type of climate has been occurred already over most territory of Ukraine and further drying is projected till the end of the $21^{\text {st }}$ century, that will be the most dangerous effects of climate change on human living conditions and ecosystems, including forests.

\section{FOREST OF UKRAINE UNDER THE CLIMATE CHANGE}

Ukraine is situated to South-East of East-European plain, 93\% of the country's territory are presented by a plain and the rest - by Ukrainian Carpathian and Crime mountains. Plain landscapes of Ukraine are presented by 3 bioclimatic zones: (1) zone of mixed coniferous-broadleaf forests (Polissja) - covered northern and western part of the country; (2) forest-steppe zone - a transition between the forest zone and steppe - this zone is mostly situated in southern part of the western region, partially in the central and eastern regions; and (3) steppe zone, which covers partially central and eastern, and completely southern part of the country. Flatland forests make up approximately $80 \%$ of forested lands in Ukraine and grow in forest, forest steppe and steppe zones and have a substantial typological diversity with about 90 forest types described by experts. As it was stated above, projected climate change should dramatically increase exposure of flatforests to unfavorable climatic conditions. To estimate this effect, we will use specially worked out indicators, namely a hydro-thermal index by Worobjov. 

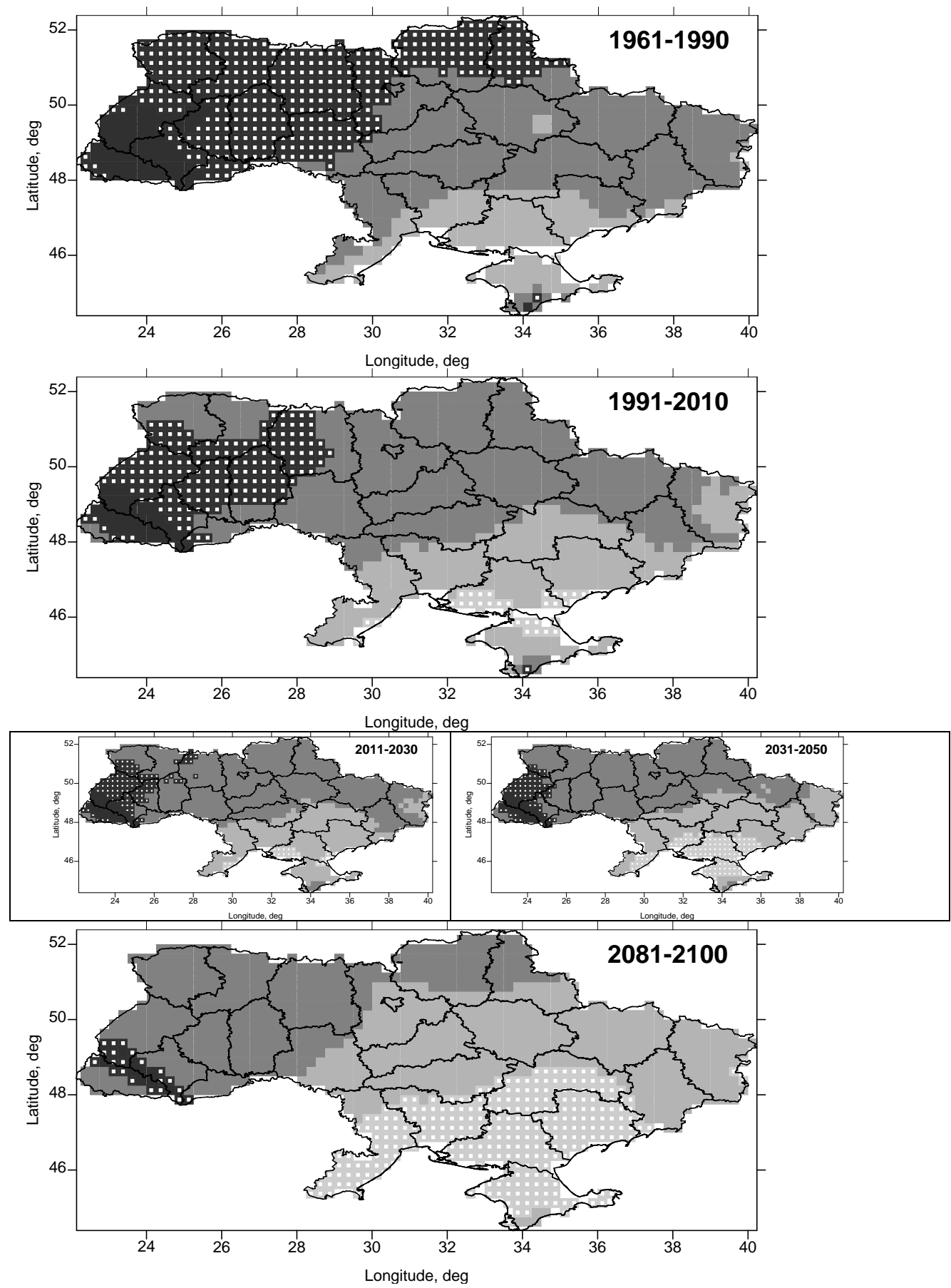

Fig. 1. Humidification coefficients with types of climates for climatic standard (19611990), modern (1991-2010) and three future pointed periods obtained by ensembles of RCMs for IPCC SRES A1B 

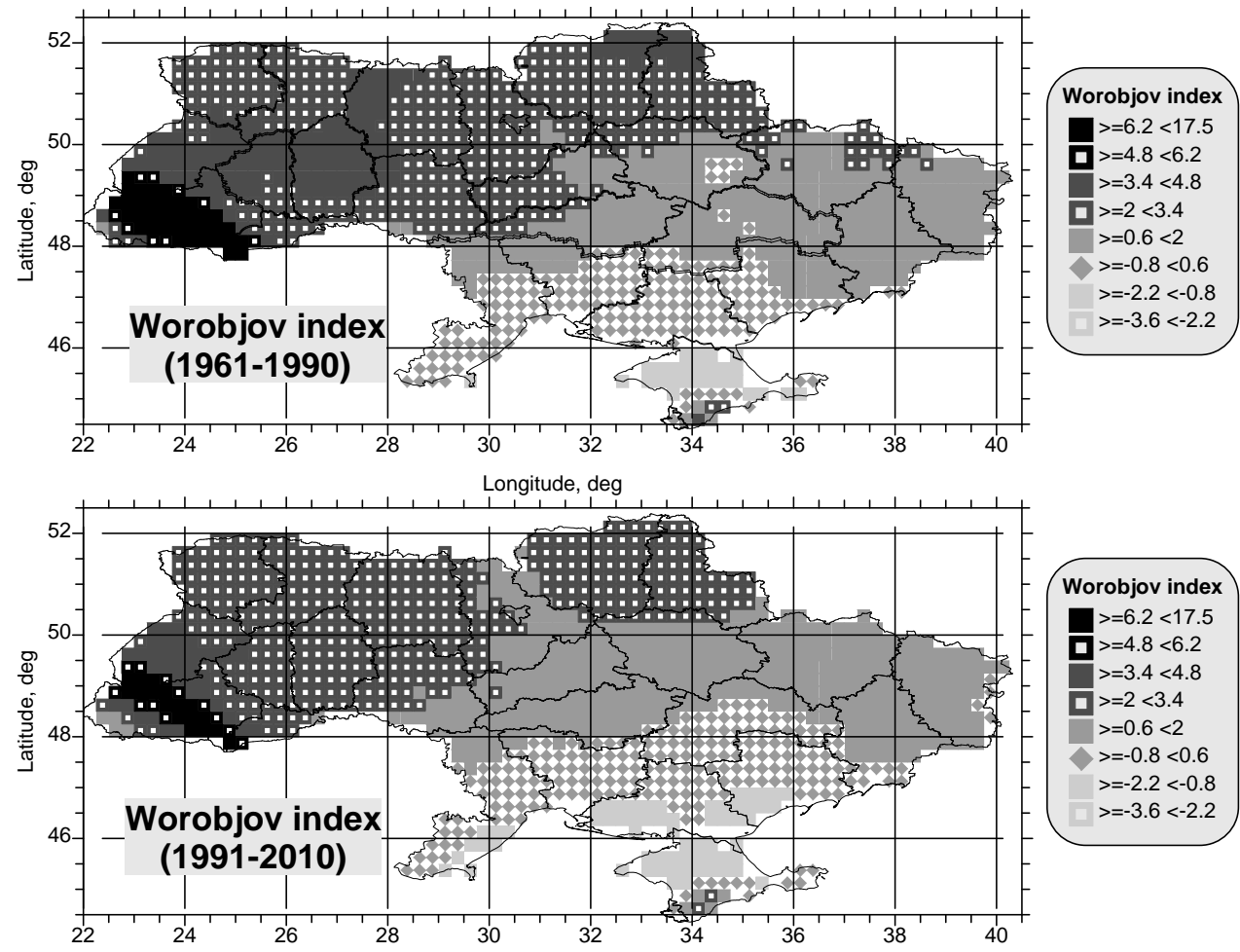

Longitude, deg
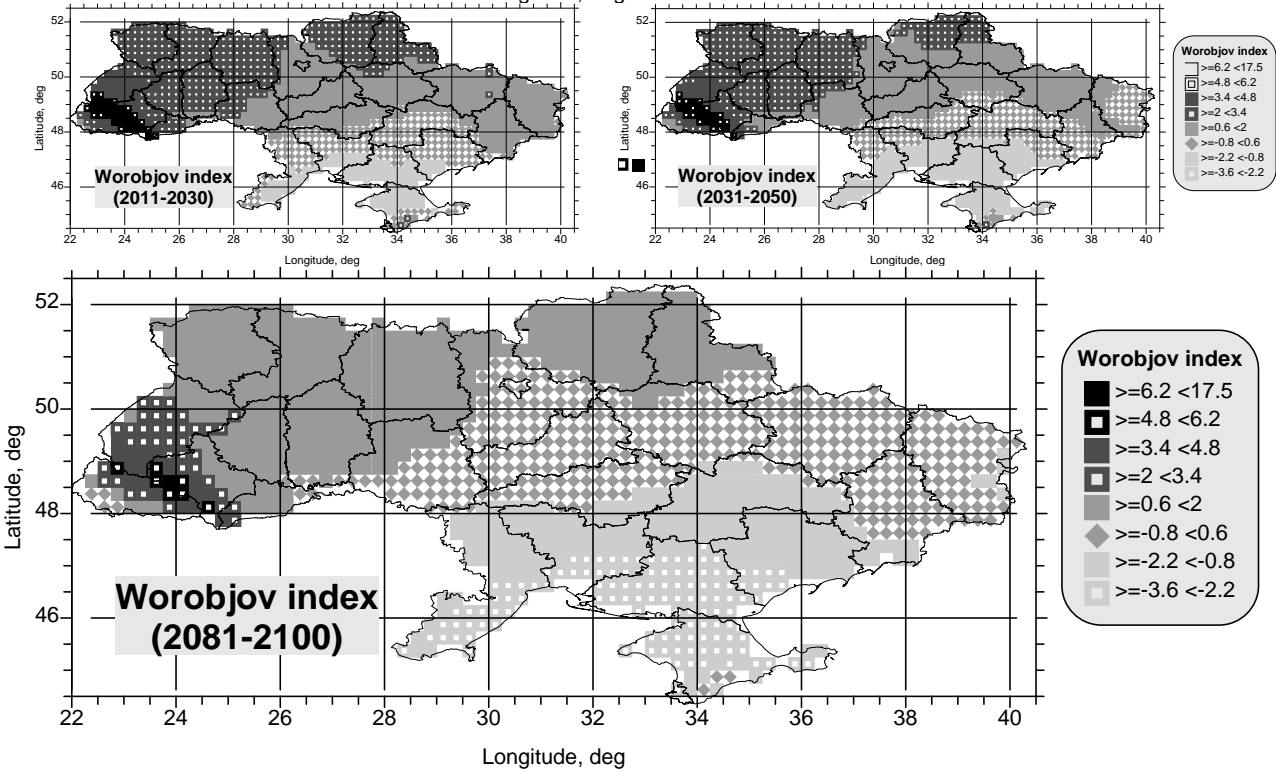

Fig. 2. W-index with types of climates for climatic standard (1961-1990) and modern (1991-2010) periods calculated by E-Obs data and for three future pointed periods obtained by ensembles of RCMs for IPCC SRES A1B scenario 
Prof. Worobjov has developed a classification of climates, as a component of forest-typological classification of tree species together with classification of edaphic conditions (Worobjov, 1961). In his approach, analysis of impacts of the most important climatic indicators - heat and humidity - on diversity of forests simultaneously relates to productivity, species composition as forest type and soil fertility. As a result, each type of forest receives the quantitative estimate: $\boldsymbol{T}$ indicator of heat availability (sum of positive monthly temperature), $\boldsymbol{A}$ - indicator of climate continentality (difference between temperature of the warmest and the coldest months of a year) and $\boldsymbol{W}$ - indicator of humidity, defined as:

$$
W=\frac{P}{T}-0.0286 * T
$$

where $\boldsymbol{P}$ - sum of precipitation during the warm period of a year $(\mathrm{mm})$.

In the interests of space only indicator $\boldsymbol{W}$ will be presented here, while all others were calculated and analyzed in the study too.

After Worobjov the types of climates by moisture availability (hydrotops) are: very dry with $\boldsymbol{W}>=-2.2<-0.8$; dry with $\boldsymbol{W}>=-0.8<+0.6$; fresh with $\boldsymbol{W}>=$ $0.6<2.0$; moist with $W>=2.0<3.4$; humid with $W>=3.4<4.8$; wet with $W>=$ $4.8<6.2$; and very wet for $W>6.2$; latter two types (wet and very wet) are characteristics only for high mountains like the Carpathians.

$\boldsymbol{W}$ index is presented in maps at Fig. 2 and as percentage of the territory of Ukraine at Fig. 3 with types of climate for all considered periods.

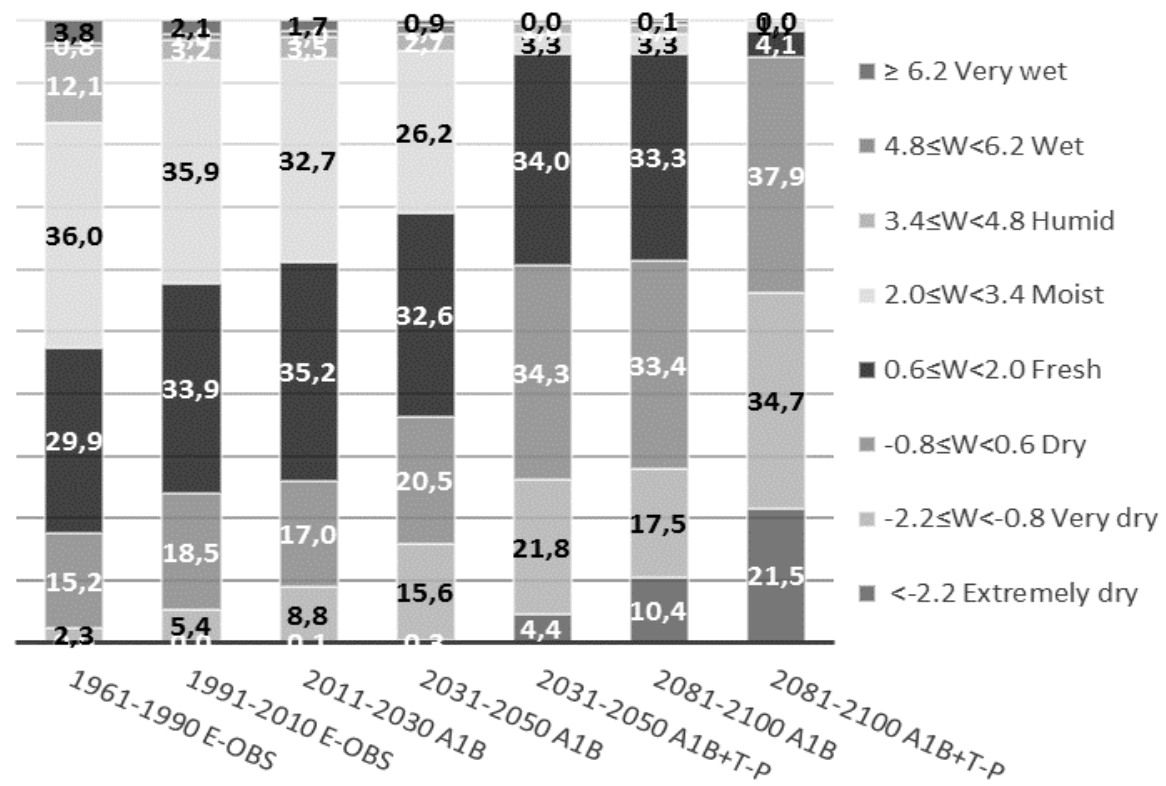

Fig. 3. Territory of Ukraine (in \%) covered by types of climate by W-index (legend on the right) for climatic standard (1961-1990) and modern (1991-2010) periods calculated by E-Obs data and for three future pointed periods obtained by ensembles of RCMs for IPCC SRES A1B and modified warmer-drier A1B+T-P scenarios 
Realization of the balanced climate change scenario A1B will lead to increasing aridity across all territory of the country comparatively with the standard climatic period accordingly to $\boldsymbol{W}$ index (Fig.2). Climate types will shift towards North. By end of the century, the area which would have conditions favorable for growth of forests (zones of humidity from very wet to fresh) will significantly decrease: such conditions in previously fresh climate will remain only in the West and North parts, and partially in the central part of the country composing one-third of the territory, while the dry and very dry types, which are typical for the steppe zone, will be formed over half territory of Ukraine. While in the current climate the very dry climate comprises $5.4 \%$ of the territory of the country (increasing since standard period from $2 / 3 \%$ ), its will increase further to $15.6 \%$ by the middle and to $17.5 \%$ at the end of the $21^{\text {st }}$ century (Fig.3). Within the considered scenario, a new type of climate is expected by end of the century - the extremely dry type, which will cover a significant part of southern Ukraine. Such changes will cause a shift of bioclimatic zones: conditions that are favorable for forest-steppe vegetation will be formed in the North, for steppe vegetation - over the rest of the territory, and for vegetation of semi-deserts - in the South, where extremely dry climate will occupy almost half of the region, and the rest will be presented by the dry type.

In order to determine the possible range of the above specified $\boldsymbol{W}$ index, the boundary values of this indicator were calculated. For these aim the confidence intervals (CI) with the confidence probability of 0.9 were assessed for the ensemble of 10RCMs for temperature and 4RCMs (the last period for 3RCMs) for precipitation. In such a way, in addition to the average realization of A1B scenario, four boundary scenarios were got: A1B+T-P, A1B+T $+\mathrm{P}, \mathrm{A} 1 \mathrm{~B}-\mathrm{T}+\mathrm{P}$ and A1B-T-P, where +/- denotes adding/subtraction of $\mathrm{CI}$ to/from the values of $\boldsymbol{T}$, and $\boldsymbol{P}$ respectively. In the interests of space only critical conditions for growth of forests and other vegetation are presented at Figs.3,4 and will be analyzed.
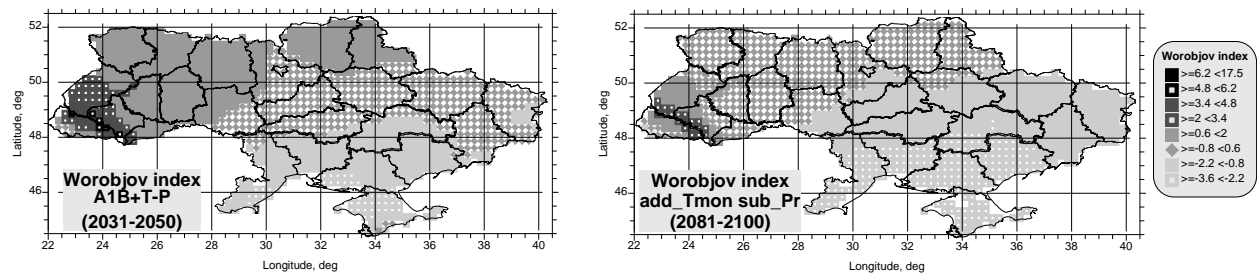

Fig. 4. W-index for periods 2031-2050 and 2081-2100 calculated by ensembles of RCMs for modified IPCC SRES A1B scenario with warmer and drier (+T/-P) conditions

According to this most tough Scenario A1B+T-P, the aridity of climate in Ukraine is expected much more severe. Comparatively with the balanced scenario, the zones of decreasing humidity will shift towards North-West. By middle of the century, zones of humid, moist and wet climate will substantially shrink in the western territories being replaced by zone of fresh climate. The area of dry climate will increase from current $18.5 \%$ to $34.3 \%$ by middle of the century and up to $37.9 \%$ by its end. Very dry climate will shift into the North and will comprise almost 35\% of the whole territory. The extreme dry conditions will appear (almost 
$5 \%$ ) in 2031-2050 and increase to $21.5 \%$ of the territory in 2081-2100, prevail over the southern region, where semi-desert vegetation will dominate almost exclusively in expected climate conditions.

\section{CONCLUSION AND DISSCUSION}

Comparison of current climatic conditions with projected showed that major features of future climate in Ukraine will be warming and aridization. The shift of zones by heat and water availability is expected from South to North. Very likely, by the middle of the $21^{\text {st }}$ century, climatic conditions in West and North parts of the country will be very similar to those we had in the central region in 1961-1990. For the same period, climate conditions in central and eastern regions will be similar to that, which is today in the southern region of Ukraine. Significant change in water supply is expected in the southern region at the end of the $21^{\mathrm{st}}$ century, that will require development of a new paradigm of risk resilient forest management, i.e. forest management, which reduces the risks of loss of forest sustainability and increases their resilience. The main features of the new paradigm should be: the need for in-depth knowledge of forest ecosystems; understand the importance of biodiversity for the long-term existence of ecosystems while preserving their steady state; understanding that natural disturbances are of critical importance as a regulator of structural and compositional heterogeneity at different scales of forest cover functioning; and the understanding that traditional forest management forms a more homogeneous forest cover than nature, that increases the likelihood of unexpected catastrophic changes due to the critical restrictions of basic natural processes in the environment.

\section{REFERENCES}

1. Gnatiuk N., Krakovska S., Shpytal T., Kostiukovskyi B., Palamarchuk L., Bilozerova A., (2013), Climate change projections for the 21st century and their impact on water resources and energy sector in Ukraine, Proc. of the International Conference on Regional Climate CORDEX (Brussels, Belgium).

2. Haylock, M.R., N. Hofstra, A.M.G. Klein Tank, E.J. Klok, P.D. Jones, M. New (2008), A European daily high-resolution gridded dataset of surface temperature and precipitation. J. Geophys. Res (Atmospheres), 113, D20119.

3. IPCC (2013): Climate Change 2013: The Physical Science Basis. Contribution of WG I to the $5^{\text {th }}$ Assessment Report of the IPCC [Stocker, T.F., et al. (eds.)]. Cambridge University Press, Cambridge, UK and New York, NY, USA, 1535 pp.

4. Krakovska S., N. Gnatiuk, L. Palamarchuk, I. Shedemenko, (2013), The best ensembles of RCMs for climate change projections in Ukraine, Geophysical Research Abstracts, Vol. 15, EGU2013-1028-3.

5. Nakićenović, N., and R. Swart (eds.) (2000): Special Report on Emissions Scenarios. A Special Report of WG III of the IPCC. Cambridge University Press, Cambridge, United Kingdom and New York, NY, USA, 599 pp.

6. Worobjov D.V. (1961), Forest-typology classification of climates. Tr. of Kharkiv Agro Institute, XXX (LXVII), 235-250 (in Russian). 